\title{
PSYCHOLOGICA
}

\section{Relações entre a linguagem oral e a linguagem escrita}

Autor(es): $\quad$ Borges, Selma Cardoso; Albuquerque, Cristina Petrucci

Publicado por: Imprensa da Universidade de Coimbra

URL

persistente:

URI:http://hdl.handle.net/10316.2/5416

DOI: $\quad$ DOI:http://dx.doi.org/10.14195/1647-8606_50_10

Accessed : $\quad$ 26-Apr-2023 15:17:21

A navegação consulta e descarregamento dos títulos inseridos nas Bibliotecas Digitais UC Digitalis, UC Pombalina e UC Impactum, pressupõem a aceitação plena e sem reservas dos Termos e Condições de Uso destas Bibliotecas Digitais, disponíveis em https://digitalis.uc.pt/pt-pt/termos.

Conforme exposto nos referidos Termos e Condições de Uso, o descarregamento de títulos de acesso restrito requer uma licença válida de autorização devendo o utilizador aceder ao(s) documento(s) a partir de um endereço de IP da instituição detentora da supramencionada licença.

Ao utilizador é apenas permitido o descarregamento para uso pessoal, pelo que o emprego do(s) título(s) descarregado(s) para outro fim, designadamente comercial, carece de autorização do respetivo autor ou editor da obra.

Na medida em que todas as obras da UC Digitalis se encontram protegidas pelo Código do Direito de Autor e Direitos Conexos e demais legislação aplicável, toda a cópia, parcial ou total, deste documento, nos casos em que é legalmente admitida, deverá conter ou fazer-se acompanhar por este aviso. 


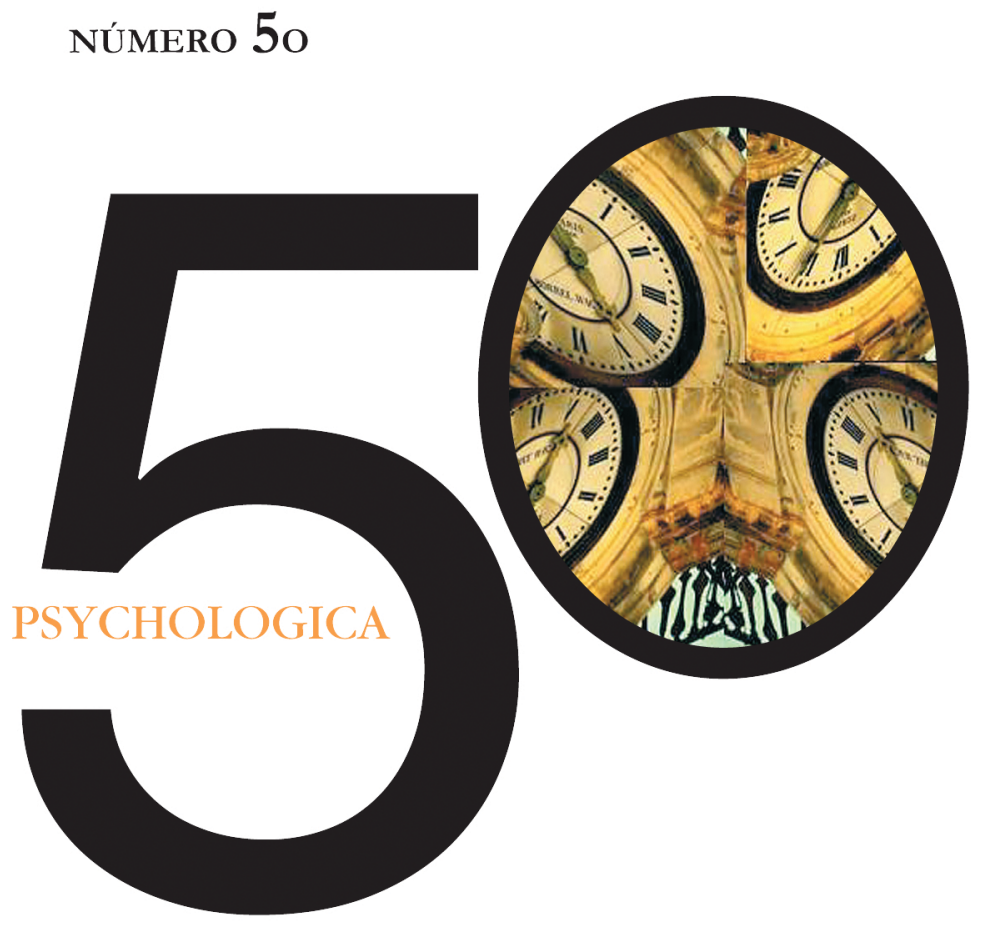

IMPRENSA DA UNIVERSIDADE DE COIMBRA

FACULDADE DE PSICOLOGIA E DE CIÊNCIAS DA EDUCAÇÃO DA UNIVERSIDADE DE COIMBRA 


\title{
Relações entre a Linguagem Oral e a Linguagem Escrita
}

\author{
Selma Cardoso Borges ${ }^{1} \&$ Cristina Petrucci Albuquerque ${ }^{2}$
}

Esta investigação pretende analisar relações entre a linguagem oral e a linguagem escrita em 80 crianças do primeiro e do segundo ano de escolaridade. Nesse sentido, foram usados instrumentos de avaliação da linguagem oral, que incorporam a Bateria de Avaliação Neuropsicológica de Coimbra (Consciência Fonológica, Nomeação Rápida e Compreensão de Instruções), e provas de escrita e de leitura do Labling e da PAL-Port. Os resultados obtidos indicaram a existência de relações estreitas entre a linguagem oral e a linguagem escrita. A Consciência Fonológica revelou estar muito associada a múltiplas medidas de avaliação do desempenho em leitura e escrita, particularmente no primeiro ano de escolaridade. Por seu turno, a Nomeação Rápida evidenciou maior relevância no segundo ano. Comparativamente às medidas anteriores, a Compreensão de Instruções mostrou estar menos relacionada com a escrita e a leitura.

PALAVRAS-CHAVE: Linguagem Oral; Escrita; Leitura.

\section{Introdução}

O acto de ler e de escrever envolve a interacção de vários processos, entre os quais se salienta o importante papel da consciência fonológica, da nomeação rápida e da compreensão sintáctica.

A relação da consciência fonológica com a leitura e a escrita tem sido enfatizada por muitos autores. Por exemplo, Wagner, Torgesen e Rashotte (1994), Tunmer, Herriman e Nesdale (1988) e Juel (1998) mostraram que as crianças mais pequenas que apresentam bons resultados em tarefas de consciência fonológica terão, posteriormente, um melhor desempenho na leitura. Por outras palavras, o desempenho na leitura, no início da escolaridade, é fortemente influenciado pela sensibilidade fonológica. Além disso, os défices na consciência fonológica são encarados como

\footnotetext{
1 Instituto de Apoio à Criança (card.selma@gmail.com)

2 Faculdade de Psicologia e de Ciências da Educação da Universidade de Coimbra
} 
um dos factores fulcrais na explicação das dificuldades ao nível da leitura. Com efeito, os maus leitores possuem representações fonológicas pobres, o que perturba as competências de elaboração de julgamentos específicos sobre a estrutura fonológica (Griffiths \& Snowling, 2001; Snowling \& Stackhouse, 1996).

Contudo, e apesar de fortes evidências da relação consciência fonológica/leitura e escrita, estas não são suficientes para implicar que o relacionamento seja causal, isto é, que contribua directamente para o progresso na aprendizagem da linguagem escrita. Neste sentido, Wagner e colaboradores (1994) salientaram que a relação causal do processamento fonológico com a leitura poderá ser de três ordens diferentes: o desenvolvimento de capacidades fonológicas facilita a aquisição de competências de leitura e de ortografia; uma criança poderá adquirir a consciência da estrutura dos sons da linguagem oral como resultado da aprendizagem da linguagem escrita; ou ainda, a possibilidade das duas alternativas estarem correctas, sendo a relação causal entre as capacidades fonológicas e de leitura bidireccional e recíproca, ou seja, a consciência preliminar da estrutura sonora da linguagem oral facilita a aprendizagem da leitura e da escrita e, por seu turno, a aprendizagem da leitura e da escrita promove o desenvolvimento da consciência fonológica.

Por outro lado, convém ter presente que a relação entre a consciência fonológica e a leitura/escrita tende a variar consoante as propriedades linguísticas das palavras, sendo mais estreita quando se trata de palavras regulares e de pseudopalavras (Cardoso-Martins \& Pennington, 2004; Nilsen \& Bourassa, 2008; Strattman \& Hodson, 2005; Wagner et al., 1994).

Para além da sensibilidade fonológica, a aquisição da leitura/escrita é fortemente influenciada pela capacidade de aceder à palavra pretendida de uma forma precisa e rápida. Neste sentido, para Nähri et al. (2004), Bowers e Wolf (1993), Manis, Bhadha e Doi (2000), entre outros, a nomeação rápida tem sido também identificada como um forte preditor das posteriores competências de leitura. Por exemplo, num estudo realizado por Cardoso-Martins e Pennington (2004), a consciência fonológica e a nomeação rápida partilharam praticamente a mesma variância na predição da leitura e da escrita. Em complemento, as crianças com dificuldades de leitura/escrita têm sido caracterizadas como apresentando graves dificuldades na nomeação rápida em série em comparação a crianças com ou sem outras dificuldades de aprendizagem (Bowers \& Wolf, 1993; Cardoso-Martins \& Pennington, 2004; Wolf et al., 2002). De acordo com Wolf et al. (2002), pode mesmo afirmar-se que a nomeação rápida distingue os disléxicos dos leitores normais em todos os estudos realizados até à actualidade, sendo os primeiros mais lentos e cometendo mais erros do que os segundos. 
No entanto, quando se atende à relação da nomeação rápida com a leitura/ escrita, há que considerar vários aspectos passiveis de influenciarem essa mesma relação. Assim, e em primeiro lugar, a relação tende a ser distinta conforme as propriedades linguísticas das palavras, sendo mais estreita quando se trata de medidas que enfatizam o conhecimento ortográfico, tais como as referentes a palavras irregulares (Cardoso-Martins \& Pennington, 2004; Manis et al., 2000). Em segundo lugar, o tipo de estímulos usado nas tarefas de nomeação também deve ser tido em conta, visto que a relação é maior quando se usam estímulos alfanuméricos (letras e dígitos) do que quando se usam objectos e cores (Manis et al., 2000; Wagner et al., 1994; Wolf et al., 2002; Wolf \& Denckla, 2005). Em terceiro lugar, admite-se que a relação possa diferir consoante se empregam tarefas que contêm estímulos pertencentes a uma única ou a várias categorias semânticas (Wagner et al., 1994; Wolf \& Denckla, 2005). Em quarto lugar, a associação pode ser mais importante quando se contemplam medidas de fluência na leitura (Cardoso-Martins \& Pennington, 2004; Escribano, 2007; Landerl, 2001).

A aprendizagem inicial da leitura pode também ser facilitada pela consciência sintáctica, pois esta última tem uma importante influência no processo de descodificação/compreensão, facultando um melhor uso das pistas sintáctico semânticas, quer no conhecimento de palavras, quer na compreensão do texto como um todo.

Segundo Tunmer (1994), o domínio sintáctico pode interagir com o desempenho da leitura a dois níveis: na possibilidade de o leitor se automonitorizar na compreensão e na facilitação do reconhecimento do valor das diferentes unidades linguísticas. Por seu turno, para Young e Bowers (1995), o reconhecimento visual das estruturas sintácticas ajuda as crianças a agrupar as diferentes unidades sintácticas de um texto, promovendo, deste modo, não só a compreensão, mas também a fluência. Assim, o domínio sintáctico desempenha um papel importante na aquisição da leitura, tal como, aliás, o indicam vários estudos (Mokhari \& Thompson, 2006; Shiotsu \& Weir, 2007; Tunmer \& Hoover, 1992).

Além disso, e apesar da evidência disponível não ser totalmente consistente (Supple, 1998), os leitores com e sem dificuldades tendem a diferenciar-se em tarefas relativas ao processamento sintáctico, nomeadamente na detecção de erros e correcção de frases (Gaux \& Gombert, 1999; Leikin \& Breznit, 2001).

Os dados revistos derivam, primordialmente, de estudos realizados na língua inglesa, cujo sistema alfabético é considerado opaco em termos das correspondências grafema/fonema. Porém, alguns estudos têm vindo a evidenciar que a aprendizagem da leitura e da escrita é mais difícil no caso do Inglês do que doutras línguas europeias, bem como que as características das línguas são passíveis de influenciarem a importância de variáveis como a consciência fonológica e a 
nomeação rápida (Escribano, 2007; Landerl, 2001). Donde a relevância de conduzir estudos relativos ao Português.

Acresce, ainda, que as relações entre as competências linguísticas e metalinguísticas e a leitura têm sido mais exploradas do que as relativas à escrita.

É, neste contexto, que se insere o presente estudo, o qual pretende contribuir para o enriquecimento das pesquisas nacionais referentes às relações entre a linguagem oral e a linguagem escrita, bem como esclarecer questões essenciais como: Existe uma relação positiva e significativa entre a consciência fonológica, a nomeação rápida e a compreensão sintáctica e provas de leitura e de escrita? Qual ou quais as competências linguísticas que estão mais relacionadas com a leitura e a escrita? A relação varia consoante o ano de escolaridade ou variáveis particulares do desempenho na leitura e na escrita?

Para o efeito, foram aplicados a 80 crianças do $1 .^{\circ}$ e do $2 .^{\circ}$ ano de escolaridade, instrumentos de avaliação da linguagem oral (Consciência Fonológica, Nomeação Rápida, Compreensão de Instruções) e provas de leitura e de escrita. Estas últimas pretendem ser diversificadas quer em termos da respectiva natureza, quer em termos dos parâmetros que são objecto de avaliação. Assim, contemplam a leitura e escrita de palavras (regulares e irregulares) e de pseudopalavras, a leitura de letras, a leitura de um texto (avaliada em função da precisão e fluência) e a elaboração de uma composição (avaliada em função de parâmetros ortográficos, linguísticos, relativos à construção da história e à fluência). O estudo abrange os anos elementares de alfabetização, uma vez que este é o período em que as crianças adquirem as principais competências inerentes à linguagem escrita, e coloca as seguintes hipóteses:

- H1: A Consciência Fonológica, a Nomeação Rápida e a Compreensão de Instruções apresentam uma relação significativa com as provas de leitura e de escrita.

- H2: De todas as medidas de avaliação da linguagem oral, a Consciência Fonológica é a que apresenta correlações mais elevadas com as diferentes medidas de leitura/escrita.

- H3: A par da Consciência Fonológica, a Nomeação Rápida e a Compreensão de Instruções também apresentam uma relação significativa com a leitura e a escrita.

- H4: A Consciência Fonológica apresenta correlações mais elevadas com a leitura e escrita de palavras regulares do que de palavras irregulares.

- H5: A Consciência Fonológica apresenta correlações mais elevadas do que as restantes medidas de linguagem oral com a leitura e escrita de pseudopalavras. 
- H6: A Nomeação Rápida apresenta correlações mais elevadas com a leitura e a escrita de palavras irregulares do que de palavras regulares.

- H7: A Nomeação Rápida apresenta correlações moderadas ou elevadas com a fluência na leitura e na escrita.

- H8: A Nomeação Rápida de Dígitos apresenta correlações mais elevadas com as diferentes variáveis de leitura e de escrita do que a Nomeação Rápida de Formas/Cores.

- H9: A Compreensão de Instruções apresenta correlações mais elevadas com a composição escrita, em particular, com variáveis sintácticas (ex., número de frases complexas, utilização de conjunções coordenativas para além do "e").

\section{Metodologia}

\subsection{Selecção da amostra}

Após deferimento de um pedido de autorização à Comissão Nacional de Protecção de Dados, foram seleccionadas três escolas do concelho de Coimbra (Escola do 1. ${ }^{\circ}$ Ciclo do Arieiro, Escola do $1 .{ }^{\circ}$ Ciclo do Bairro Norton de Matos e Escola do 1. ${ }^{\circ}$ Ciclo Paulo Quintela), em função da respectiva localização urbana e suburbana. Seguidamente, foi elaborado um pedido de autorização ao respectivo Agrupamento de Escolas, bem como ao Conselho Executivo de cada escola.

Uma vez seleccionadas as escolas, contemplaram-se as crianças que frequentavam o $1 .^{\circ}$ e o $2 .^{\circ}$ ano de escolaridade, sem necessidades educativas especiais ou apoio do ensino especial, solicitando-se aos professores, de turmas seleccionadas aleatoriamente, que indicassem crianças oriundas de diferentes níveis socioeconómicos e com diferentes níveis de desempenho escolar. De seguida, foi enviado um pedido de autorização aos encarregados de educação das crianças seleccionadas.

\subsection{Caracterização da amostra}

A amostra é constituída por 80 sujeitos, 40 do $1 .^{\circ}$ ano e 40 do $2 .^{\circ}$ ano, distribuídos pelas três escolas: a escola do $1 .^{\circ}$ Ciclo do Bairro Norton de Matos com 26 sujeitos, sendo que, 13 são do $1 .^{\circ}$ ano e 13 são do $2 .^{\circ}$; a escola do $1 .^{\circ}$ Ciclo Paulo Quintela com 27 sujeitos, sendo que, 14 são do $1 .^{\circ}$ ano e 13 são do $2 .^{\circ}$; e por último, a escola do $1 .{ }^{\circ}$ Ciclo do Arieiro igualmente com 27 sujeitos, dos quais 13 são do $1 .^{\circ}$ ano e 14 são do $2 .^{\circ}$. Da amostra fazem parte $43(53.25 \%)$ rapazes e $37(46.25 \%)$ raparigas, com idades compreendidas entre os 6 e os 8 anos $(M=6.73$; d.p. $=.66)$. 


\subsection{Instrumentos}

Com o objectivo de avaliar a linguagem oral foram aplicados testes de Consciência Fonológica (CF), de Nomeação Rápida (NR) e de Compreensão de Instruções (Cl) da Bateria de Avaliação Neuropsicológica de Coimbra (BANC; Simões et al., 2000). Para avaliar a linguagem escrita foram usadas Provas do Labling (Laboratório de Estudos de Linguagem, Centro de Estudos Egas Moniz; Loureiro, Silva \& Fernandes, 2002), nomeadamente a escrita de palavras por ditado, a leitura de palavras, a leitura de letras e a leitura de um texto para o $1 .{ }^{\circ}$ e $2 .^{\circ}$ ano de escolaridade. Foram ainda usados os testes de escrita de pseudopalavras por ditado, bem como de leitura de pseudopalavras da PAL-Port (Bateria de Avaliação Psicolínguística das Afasias e de Outras Perturbações da Linguagem para a População Portuguesa; Festas et al., 2006) e o Teste de Escrita Espontânea do Test of Written LanguageThird Edition (TOWL- 3; Hammill \& Larsen, 1996).

O recurso aos testes de linguagem oral da BANC deveu-se ao facto de vários estudos atestarem que as qualidades psicométricas destes testes são amplamente satisfatórias, quer em termos de análise dos itens (Albuquerque, Martins $\&$ Simões, 2007), quer em termos de precisão e validade. Por exemplo, a validade discriminante dos testes de linguagem oral foi comprovada em estudos relativos a crianças vítimas de traumatismo crânio-encefálico (Santos, 2006), a crianças com dificuldades de a prendizagem (Simões et al., 2007), a crianças com epilepsia (Lopes, 2007) e a crianças com Perturbação de Oposição e Desafio (Sá, 2007).

No que respeita aos testes de linguagem escrita, dada a ausência de testes de leitura e escrita aferidos para a população infantil e juvenil portuguesa, optámos por instrumentos de avaliação que satisfizessem um ou mais dos seguintes critérios: baseados ou adaptados a partir de instrumentos de avaliação detentores de prestígio internacional (PAL-Port desenvolvida a partir da Psycholinguistic Assessment of Language; Teste de Escrita Espontânea adaptado do TOWL-3); elaborados por equipas multidisciplinares constituídas, entre outros profissionais, por linguistas e/ou psicolinguistas (Provas do Labling; PAL-Port); com estudos psicométricos em curso (PAL- Port) ou já realizados (Loureiro et al., 2002; Martins, 2005).

No âmbito de uma caracterização sucinta dos instrumentos empregues, começamos por apontar que os testes de Consciência Fonológica são constituídos por um teste de Eliminação e um teste de Substituição. No teste de Eliminação, solicita-se à criança que pronuncie palavras sem um determinado som. No teste de Substituição, solicita-se à criança que pronuncie palavras depois de Ihes ter retirado um ou mais sons, substituindo-os por outros. Cada resposta correcta é cotada com um ponto.

Os testes de Nomeação Rápida compreendem um teste de Nomeação de Cores, para crianças com 5 e 6 anos de idade, um de Nomeação de Dígitos e um de 
Nomeação de Formas e Cores, ambos para indivíduos com idades entre os 7 e os 15 anos. Nestes testes, pede-se aos sujeitos para nomearem, o mais depressa possivel, estímulos visuais, impressos num cartão, que lhes são familiares e que se repetem em sequências aleatórias. Note-se que, enquanto na Nomeação de Cores e Dígitos o sujeito nomeia apenas estes estímulos, na Nomeação de Formas e Cores, o sujeito deve referir estas duas dimensões. A cotação traduz-se no tempo que os sujeitos despendem na nomeação dos estímulos.

O teste de Compreensão de Instruções é constituido por 27 instruções apresentadas oralmente à criança, as quais Ihe solicitam que aponte para uma ou mais figuras dispostas num cartão. As 27 instruções distribuem-se, em igual número, por três partes, envolvendo graus de complexidade e materiais diferentes. Assim, as nove instruções da primeira parte requerem que a criança aponte para um ou mais cãezinhos, de entre um conjunto de oito, que diferem, entre si, de acordo com determinados atributos figurativos. Em casos pontuais, é requerida a compreensão de conceitos relacionados com a localização, identidade e coordenação. Por seu turno, as instruções da segunda e terceira parte solicitam à criança que aponte para uma ou mais figuras geométricas de entre um total de nove, implicando a compreensão de conceitos de coordenação, sequência, localização, inversão temporal, inclusão/exclusão e identidade/diferença. Note-se que as instruções da terceira parte são mais complexas do que as da segunda parte em termos dos conceitos implicados. Neste teste, atribui-se um ponto a cada resposta correcta.

No que respeita às provas de escrita de palavras por ditado e de leitura de palavras, foram usadas 34 palavras na escrita e 44 na leitura. As palavras dividem-se por critérios de regularidade (20 palavras na escrita e 16 na leitura) e irregularidade (14 palavras na escrita e 28 na leitura), enquadrando-se nesta última palavras que não apresentam uma correspondência simples entre o fonema e o grafema. É concedido um ponto para cada palavra correctamente escrita/lida. Foi calculado um resultado para palavras regulares, para palavras irregulares e para a soma das duas categorias.

Quanto à escrita de pseudopalavras por ditado e à leitura de pseudopalavras, foram utilizadas 34 palavras, sendo 10 de ortografia e fonologia simples, 10 de ortografia simples e fonologia complexa e 14 de ortografia complexa e fonologia simples. Nas pseudopalavras de ortografia e fonologia simples, a forma fónica possui unicamente uma representação gráfica, sendo esta uma relação unívoca de "um para um". As pseudopalavras de ortografia simples e fonologia complexa distinguem-se relativamente às do grupo anterior, pelo facto de apresentarem grupos consonânticos em ataque de sílaba inicial. No grupo de pseudopalavras de ortografia complexa e fonologia simples, uma dada sequência fónica admite mais do que uma representação gráfica, isto é, para a representação gráfica de um 
dado som, existem múltiplas sequências gráficas, cuja co-presença condiciona a pronúncia. Neste teste, atribui-se um ponto por cada pseudopalavra bem escrita/ lida. Foi calculado um resultado para as diferentes categorias de pseudopalavras, bem como um resultado total correspondente à soma destas três dimensões.

Na avaliação espontânea da expressão escrita do Test of Written Language-Third Edition (TOWL-3), o examinador mostra à criança uma imagem alusiva a uma cena espacial e solicita que esta escreva uma história acerca da mesma. A criança tem 15 minutos para elaborar a história. Se aos 15 minutos, esta ainda não tiver terminado a tarefa, dever-se-á colocar um $X$ na composição e permitir que continue até concluir a mesma. A cotação é feita com base num determinado número de parâmetros, tais como: Convenções Contextuais (número total de palavras não duplicadas incorrectamente escritas, número total de palavras incorrectamente escritas); Linguagem Contextual (número de frases complexas, utilização de conjunções coordenativas para além do "e", número total de palavras correctamente escritas com 3 ou mais sílabas); e Construção da História (início da história, sequência da história, prosa ou forma de escrever). Por último, teve-se em conta o número de palavras aos 15 minutos e o número total de palavras. Ressalva-se que a avaliação de alguns parâmetros da composição escrita é algo esquemática e imprecisa. Referimo-nos, essencialmente, a todos os parâmetros pertencentes à construção da história, os quais são cotados com uma escala de o a 2 pontos.

No teste leitura de letras, são apresentadas 12 letras, sendo a criança solicitada a dizer o nome das mesmas. É atribuído um ponto por cada nome de letra correcto.

A leitura do texto "As férias", para o $1 .^{\circ}$ ano de escolaridade, compreende um número total de 58 palavras, com frases, predominantemente curtas e simples e vocabulário pouco complexo. Para o $2 .^{\circ}$ ano, o texto seleccionado, "Os pintainhos da Teresa”, é composto por 74 palavras, com frases que alternam entre simples e complexas e vocabulário ligeiramente mais elaborado que o relativo ao ano anterior. Na avaliação da leitura dos textos atendeu-se: ao número de palavras correctamente lidas e à fluência, a qual foi determinada com base no tempo total de leitura e com base no número total de palavras correctamente lidas dividido pelo tempo total de leitura.

\subsection{Procedimento}

A recolha da amostra teve lugar desde o mês de Março até à primeira semana do mês de Junho de 2008. A avaliação foi realizada na escola de cada criança, num local sossegado e isento de estímulos distractores. 
A aplicação dos vários testes foi feita de forma individual, seguindo uma ordem pré-definida, que intercalava instrumentos de avaliação da linguagem oral e escrita.

\section{3 - Resultados}

Nos Quadros 1 e 2 são apresentadas as médias, os desvios-padrão, os máximos e os mínimos dos instrumentos utilizados na avaliação da linguagem oral e da linguagem escrita (leitura/escrita). Note-se que todos os resultados se reportam a valores brutos, uma vez que, como apenas se dispunha de resultados padronizados para os testes de linguagem oral, se optou por utilizar somente os primeiros.

Quadro 1. Média, Desvio-padrão, Máximo, Mínimo dos testes de linguagem oral

\begin{tabular}{lrrrrr}
\hline & N & M & Dp & Max & Min \\
\hline Consciência F elim $^{1}$ & 80 & 10.48 & 4.71 & 19 & 0 \\
Consciência F subs $^{2}$ & 80 & 10.36 & 4.62 & 18 & 0 \\
Nomeação Rápida Cores & 33 & 55.45 & 18.39 & 103 & 34 \\
Nomeação Rápida Dígitos & 47 & 34.77 & 11.13 & 98 & 24 \\
Nomeação Rápida f/c ${ }^{3}$ & 47 & 129.04 & 46.30 & 341 & 77 \\
Compreensão de Instruções & 80 & 17.56 & 4.67 & 26 & 3 \\
\hline
\end{tabular}

${ }^{1}$ Consciência F elim - Consciência Fonológica eliminação; ${ }^{2}$ Consciência F subs - Consciência Fonológica substituição; ${ }_{3}^{3}$ Nomeação 5 Rápida f/c - Nomeação Rápida de Formas/Cores.

Como podemos constatar no Quadro 1, os resultados obtidos ao nível das medidas de linguagem oral, apresentam uma grande amplitude, o que demonstra a heterogeneidade da amostra, em termos de desempenho. Chama-se a atenção para o facto do número de sujeitos ser mais reduzido na Nomeação Rápida de Cores, Dígitos e Formas/Cores, uma vez que, de acordo com as normas de administração da BANC, estes testes se aplicam a faixas etárias específicas.

Quadro 2. Média, Desvio-padrão, Máximo, Mínimo das provas de escrita e de leitura

\begin{tabular}{|c|c|c|c|c|c|}
\hline & $\mathrm{N}$ & M & $\mathrm{Dp}$ & Max & Min \\
\hline Escrita Palavras Irregulares & 80 & 6.35 & 3.45 & 12 & o \\
\hline Escrita Palavras Regulares & 80 & 10.43 & 4.67 & 18 & 1 \\
\hline Escrita Palavras Total & 80 & 16.77 & 7.73 & 28 & 1 \\
\hline Escrita Pseudopalavras O/F Simples' & 80 & 7.60 & 1.98 & 10 & o \\
\hline Escrita Pseudopalavras OC/FS² & 80 & 6.76 & 3.63 & 12 & o \\
\hline Escrita Pseudopalavras OS/FC 3 & 80 & 5.35 & 3.30 & 10 & o \\
\hline Escrita Pseudopalavras Total & 80 & 19.71 & 7.95 & 32 & o \\
\hline Número Total Palavras N D Inc Esc. ${ }^{4}$ & 80 & 7.41 & 5.87 & 30 & $\mathrm{O}$ \\
\hline Número Total Palavras Inc Esc. ${ }^{5}$ & 80 & 9.05 & 7.01 & 35 & o \\
\hline Número Total Frases Complexas & 80 & 1.54 & 1.81 & 9 & o \\
\hline Conjunções Coordenativas & 80 & .56 & .59 & 2 & o \\
\hline Número Palavras Correct Esc. $3^{6}$ & 80 & 6.11 & 6.63 & 26 & o \\
\hline Início História & 80 & .63 & .60 & 2 & o \\
\hline
\end{tabular}


Quadro 2. (continuação)

\begin{tabular}{|c|c|c|c|c|c|}
\hline & $\mathrm{N}$ & M & Dp & Max & Min \\
\hline Sequência História & 80 & .75 & .82 & 3 & o \\
\hline Prosa Forma Escrever & 80 & .51 & .66 & 2 & o \\
\hline Número Total Palavras 15min & 80 & 54.07 & 32.66 & 165 & 7 \\
\hline Número Total Palavras & 80 & 62.60 & 47.32 & 284 & 7 \\
\hline Leitura Letras & 80 & 10.89 & .86 & 12 & 9 \\
\hline Leitura Palavras Regulares & 80 & 23.47 & 6.31 & 28 & 4 \\
\hline Leitura Palavras Irregulares & 80 & 11.05 & 4.90 & 16 & $\mathrm{O}$ \\
\hline Leitura Palavras Total & 80 & 34.53 & 10.92 & 44 & 4 \\
\hline Leitura Pseudopalavras O/F Simples7 & 80 & 9.00 & 2.00 & 10 & o \\
\hline Leitura Pseudopalavras OC/FS & 80 & 10.65 & 4.08 & 14 & 1 \\
\hline Leitura Pseudopalavras OS/FC9 & 80 & 8.08 & 2.85 & 10 & o \\
\hline Leitura Pseudopalavras Total & 80 & 27.73 & 7.91 & 34 & 2 \\
\hline Leitura Texto Tempo Total & 80 & 144.14 & 140.09 & 775 & 33 \\
\hline Leitura Texto Total Palavras & 80 & 60.41 & 13.85 & 74 & 22 \\
\hline Leitura Texto Tempo/Palavras & 80 & .82 & .56 & 2.1 & .03 \\
\hline
\end{tabular}

${ }^{1}$ Escrita Pseudopalavras O/F Simples - Escrita de Pseudopalavras de Ortografia e Fonologia Simples; ${ }^{2}$ Escrita Pseudopalavras OC/FS - Escrita de Pseudopalavras de Ortografia Complexa e Fonologia Simples; ${ }^{3}$ Escrita Pseudopalavras OS/FC - Escrita de Pseudopalavras de Ortografia Simples e Fonologia Complexa; ${ }^{4}$ Número Total Palavras N D Inc Esc. - Número Total de Palavras Não Duplicadas Incorrectamente Escritas; 5 Número Total Palavras Inc Esc. - Número Total de Palavras Incorrectamente Escritas; ${ }^{6}$ Número Palavras Correct Esc. 3 - Número de Palavras Correctamente Escritas com 3 ou mais Sílabas; ${ }^{7}$ Leitura Pseudopalavras O/F simples - Leitura de Pseudopalavras de Ortografia Simples e Fonologia Simples; ${ }^{8}$ Leitura Pseudopalavras OC/FS - Leitura de Pseudopalavras de Ortografia Complexa e Fonologia Simples; ${ }^{9}$ Leitura Pseudopalavras OS/FC - Leitura de Pseudopalavras de Ortografia Simples e Fonologia Complexa.

$\mathrm{Na}$ avaliação da escrita e da leitura, as crianças obtêm resultados médios mais elevados nas palavras regulares do que nas irregulares. Através do recurso ao teste $t$ de Student para amostras emparelhadas ( $t(79)=-13.208$; $p<.01)$, comprovou-se a existência de diferenças estatisticamente significativas entre a escrita de palavras regulares e irregulares. O mesmo padrão de resultados foi obtido para a leitura $(\mathrm{t}(79)=-38.404 ; \mathrm{p}<.01)$. Além disso, e no que respeita às pseudopalavras, os resultados são mais baixos na escrita e leitura de palavras de ortografia simples e fonologia complexa. Os resultados obtidos na ANOVA para medidas repetidas indicam que existem diferenças estatisticamente significativas entre as três categorias de pseudopalavras quer ao nível da escrita $(F(2,158)=29.914 ; p<$ .01), quer ao nível da leitura $F(2,158)=34,442 ; \mathrm{p}<.01$ ). Recorda-se que o número de pseudopalavras é igual nas provas de leitura e de escrita, enquanto que o número de palavras regulares e irregulares é ligeiramente maior na leitura. Por conseguinte, é possível notar que o desempenho é superior nas tarefas de leitura de pseudopalavras do que nas tarefas de escrita das mesmas, tal como o comprova a comparação relativa aos respectivos resultados totais $(\mathrm{t}(79)=13,615 ; \mathrm{p}<$ .01). Idêntica tendência é também observável no que respeita à leitura e escrita de palavras, não obstante as diferenças no respectivo número $(\mathrm{t}(79)=17.750$; $\mathrm{p}<$ 
.01). Em suma, os resultados sugerem haver uma maior dificuldade ao nível de tarefas relacionadas com a escrita, o que se poderá prender com as características da Língua Portuguesa em termos de transparência da cadeia da fala, a qual é menor na escrita do que na leitura.

Quanto à composição (TOWL-3), os resultados sugerem a predominância de frases simples. No entanto, uma análise complementar dos resultados por ano de escolaridade atesta que se trata de uma verificação aplicável, essencialmente, ao $1 .^{\circ}$ ano de escolaridade. Evidencia-se ainda uma pobreza na utilização de conjunções coordenativas para além do "e", sendo esta também mais marcada no $1 .^{\circ}$ ano. Tendo em conta o número total de palavras utilizadas pelas crianças, o número médio de palavras não duplicadas incorrectamente escritas e o número total de palavras incorrectamente escritas afiguram-se aceitáveis. Como se poderia esperar, nota-se que existe uma ligeira discrepância do $1 .^{\circ}$ para o $2 .^{\circ}$ ano de escolaridade, sendo que no primeiro as crianças cometem maior número de erros. Os resultados sugerem que as composições foram, em regra, pequenas.

A leitura de letras também obteve um resultado elevado, uma vez que o conhecimento do alfabeto é uma tarefa claramente dominada pelas crianças. Da análise dos protocolos, verificou-se que a única letra em que as crianças manifestavam alguns erros era a letra " $C$ ", em que, em lugar do nome da letra, as crianças identificavam um dos valores fonéticos da mesma $(\langle K\rangle)$.

Quadro 3. Correlações entre a linguagem oral, a escrita e a leitura para o total da amostra

\begin{tabular}{lcccccc}
\hline & $\begin{array}{c}\mathrm{CFe}^{1} \\
(\mathrm{~N}=80)\end{array}$ & $\begin{array}{c}\mathrm{CFs}^{2} \\
(\mathrm{~N}=80)\end{array}$ & $\begin{array}{c}\mathrm{NRc}^{3} \\
(\mathrm{~N}=33)\end{array}$ & $\begin{array}{c}\mathrm{NRd}^{4} \\
(\mathrm{~N}=47)\end{array}$ & $\begin{array}{c}\mathrm{NRf} / \mathrm{c}^{5} \\
(\mathrm{~N}=47)\end{array}$ & $\begin{array}{c}\mathrm{Cl}^{6} \\
(\mathrm{~N}=80)\end{array}$ \\
\hline Escrita Palavras Irregulares & $.60^{* *}$ & $.68^{* *}$ & -.15 & $-.52^{* *}$ & $-.63^{* *}$ & $.41^{* *}$ \\
Escrita Palavras Regulares & $.62^{* *}$ & $.69^{* *}$ & -.19 & $-.47^{* *}$ & $-.51^{* *}$ & $.42^{* *}$ \\
Escrita Palavras Total & $.65^{* *}$ & $.71^{* *}$ & -.18 & $-.54^{* *}$ & $-.61^{* *}$ & $.44^{* *}$ \\
Escrita Pseudopalavras O/F Simples7 & $.44^{* *}$ & $.46^{* *}$ & -.33 & $-.52^{* *}$ & $-.35^{*}$ & .22 \\
Escrita Pseudopalavras OC/FS & $.61^{* *}$ & $.68^{* *}$ & -.23 & $-.49^{* *}$ & $-.51^{* *}$ & $.32^{* *}$ \\
Escrita Pseudopalavras OS/FC9 & $.62^{* *}$ & $.63^{* *}$ & -.34 & $-.39^{* *}$ & $-.39^{* *}$ & $.40^{* *}$ \\
Escrita Pseudopalavras Total & $.64^{* *}$ & $.67^{* *}$ & -.33 & $-.51^{* *}$ & $-.46^{* *}$ & $.37^{* *}$ \\
Número Total Palavras N D Inc Esc. ${ }^{10}$ & $-.26^{*}$ & -.17 & -.19 & $.51^{* *}$ & .23 & -.03 \\
Número Total Palavras Inc Esc." & $-.31^{* *}$ & $-.26^{* *}$ & -.16 & $.40^{* *}$ & .18 & -.04 \\
Número Total Frases Complexas & $.34^{* *}$ & $.49^{* *}$ & -.22 & -.21 & $-.44^{* *}$ & $.30^{* *}$ \\
Conjunções Coordenativas & $.42^{* *}$ & $.49^{* *}$ & -.07 & -.23 & -.24 & $.33^{* *}$ \\
Número Palavras Correct EsC. $3^{12}$ & $.43^{* *}$ & $-.58^{* *}$ & -.18 & -.23 & $-.44^{* *}$ & $.43^{* *}$ \\
Início História & $.33^{* *}$ & $.48^{* *}$ & -.16 & -.22 & $-.34^{*}$ & $.29^{* *}$ \\
Sequência História & $.53^{* *}$ & $.64^{* *}$ & -.32 & -.23 & $-.39^{* *}$ & $.50^{* *}$ \\
Prosa Forma Escrever & $.49^{* *}$ & $.57^{* *}$ & -.26 & -.21 & $-.41^{* *}$ & $.39^{* *}$ \\
Número Total Palavras 15min & $.30^{* *}$ & $.50^{* *}$ & -.17 & -.20 & $-.45^{* *}$ & $.39^{* *}$ \\
Número Total Palavras & $.28^{*}$ & $.42^{* *}$ & -.24 & -.18 & $-.36^{* *}$ & $.32^{* *}$ \\
\hline
\end{tabular}


Quadro 3. (continuação)

\begin{tabular}{lcccccc}
\hline & $\begin{array}{c}\mathrm{CFe}^{1} \\
(\mathrm{~N}=80)\end{array}$ & $\begin{array}{c}\mathrm{CF}^{2} \\
(\mathrm{~N}=80)\end{array}$ & $\begin{array}{c}\mathrm{NRC}^{3} \\
(\mathrm{~N}=33)\end{array}$ & $\begin{array}{c}\mathrm{NRd}^{4} \\
(\mathrm{~N}=47)\end{array}$ & $\begin{array}{c}\mathrm{NRf} / \mathrm{c}^{5} \\
(\mathrm{~N}=47)\end{array}$ & $\begin{array}{c}\mathrm{Cl}^{6} \\
(\mathrm{~N}=80)\end{array}$ \\
\hline Leitura Letras & $.40^{* *}$ & $.47^{* *}$ & -.11 & -.05 & -.16 & $.39^{* *}$ \\
Leitura Palavras Regulares & $.64^{* *}$ & $.67^{* *}$ & -.19 & $-.64^{* *}$ & $-.59^{* *}$ & $.44^{* *}$ \\
Leitura Palavras Irregulares & $.65^{* *}$ & $.69^{* *}$ & -.18 & $-.55^{* *}$ & $-.62^{* *}$ & $.47^{* *}$ \\
Leitura Palavras Total & $.66^{* *}$ & $.70^{* *}$ & -.19 & $-.62^{* *}$ & $-.62^{* *}$ & $.46^{* *}$ \\
Leitura Pseudopalavras O/F Simples'3 & $.36^{* *}$ & $.46^{* *}$ & -.00 & $-.76^{* *}$ & $-.55^{* *}$ & .18 \\
Leitura Pseudopalavras OC/FS'4 & $.56^{* *}$ & $.56^{* *}$ & -.13 & $-.66^{* *}$ & $-.56^{* *}$ & $.32^{* *}$ \\
Leitura Pseudopalavras OS/FC15 & $.55^{* *}$ & $.60^{* *}$ & -.15 & $-.60^{* *}$ & $-.64^{* *}$ & $.38^{* *}$ \\
Leitura Pseudopalavras Total & $.58^{* *}$ & $.62^{* *}$ & -.12 & $-.72^{* *}$ & $-.63^{* *}$ & $.35^{* *}$ \\
Leitura Texto Tempo Total & $-.52^{* *}$ & $-.57^{* *}$ & -.20 & $.78^{* *}$ & $.64^{* *}$ & $.36^{* *}$ \\
Leitura Texto Total Palavras & $.55^{* *}$ & $.64^{* *}$ & -.14 & $-.63^{* *}$ & $-.58^{* *}$ & $.47^{* *}$ \\
Leitura Texto Tempo/Palavras & $.52^{* *}$ & $.62^{* *}$ & -.25 & $-.41^{* *}$ & $-.54^{* *}$ & $.40^{* *}$ \\
\hline
\end{tabular}

${ }^{*} p<.05^{* *} p<.01$

${ }^{1} \mathrm{CFe}$ - Consciência Fonológica eliminação; ${ }^{2} \mathrm{CFs}$ - Consciência Fonológica substituição; ${ }^{3} \mathrm{NRc}$ - Nomeação Rápida de cores; ${ }^{4}$ NRd - Nomeação Rápida de dígitos; ${ }^{5} \mathrm{NRf} / \mathrm{C}$ - Nomeação Rápida de formas/cores; ${ }^{6} \mathrm{Cl}$ - Compreensão de Instruções; 7 Escrita Pseudopalavras O/F Simples - Escrita de Pseudopalavras de Ortografia e Fonologia Simples; ${ }^{8}$ Escrita Pseudopalavras OC/FS - Escrita de Pseudopalavras de Ortografia Complexa e Fonologia Simples; ${ }^{9}$ Escrita Pseudopalavras OS/FC - Escrita de Pseudopalavras de Ortografia Simples e Fonologia Complexa; ${ }^{10}$ Número Total Palavras N D Inc Esc. - Número Total de Palavras Não Duplicadas Incorrectamente Escritas; " Número Total Palavras Inc Esc. - Número Total de Palavras Incorrectamente Escritas; ${ }^{12}$ Número Palavras Correct Esc. 3 - Número de Palavras Correctamente Escritas com 3 ou mais Sílabas; ${ }^{13}$ Leitura Pseudopalavras O/F simples - Leitura de Pseudopalavras de Ortografia Simples e Fonologia Simples; ${ }^{14}$ Leitura Pseudopalavras OC/FS - Leitura de Pseudopalavras de Ortografia Complexa e Fonologia Simples; ${ }^{15}$ Leitura Pseudopalavras OS/FC - Leitura de Pseudopalavras de Ortografia Simples e Fonologia Complexa.

Examinaremos agora as relações entre os resultados obtidos na linguagem oral e na escrita, as quais foram determinadas através do cálculo de correlações de Pearson. Tendo em conta a amostra total, os resultados apontam para a existência de uma forte relação entre a linguagem oral e a linguagem escrita (cf. Quadro 3). Atendendo ao conjunto dos testes utilizados para a avaliação da linguagem oral, os de Consciência Fonológica (Eliminação e Substituição), foram os instrumentos que provaram estar mais correlacionados com a leitura e a escrita. Esta dimensão apresenta resultados muito significativos em relação à escrita de palavras regulares e irregulares, havendo uma ligeira superioridade nas primeiras. Relativamente à leitura, os resultados apontam para uma ligeira superioridade da associação com as palavras irregulares, comparativamente às regulares. Registaram-se também correlações significativas entre estas medidas e a escrita e leitura de pseudopalavras, sendo as mais elevadas as respeitantes às pseudopalavras de ortografia complexa e fonologia simples, bem como de ortografia simples e fonologia complexa. A relação entre a Consciência Fonológica e a linguagem escrita está também patente na elaboração da composição, bem como na leitura do texto.

Note-se que, salvo algumas excepções, o teste de Substituição obteve valores mais elevados com as diferentes provas de escrita e de leitura do que o teste de Eliminação. 
Embora as medidas de Consciência Fonológica se tenham evidenciado, os testes de Nomeação Rápida também mostraram estar fortemente relacionados com a leitura e a escrita. A este respeito, começamos por notar que se trata, maioritariamente, de correlações negativas porque a um resultado mais elevado na Nomeação Rápida corresponde um tempo de nomeação mais longo, isto é, um pior desempenho, ao contrário do que acontece com a generalidade dos resultados relativos à leitura e à escrita. No entanto, realça-se que esta relação é significativa apenas na Nomeação de Dígitos e de Formas/Cores, já que a Nomeação de Cores não mostrou estar associada com a linguagem escrita.

Pode-se, também, observar que a associação entre a Nomeação Rápida de Dígitos e Formas/Cores com a escrita e leitura de palavras é, salvo uma excepção (Nomeação Rápida de Dígitos e leitura de palavras irregulares), ligeiramente maior quando se trata de palavras irregulares do que de palavras regulares. No que se refere à escrita e leitura de pseudopalavras, a Nomeação de Dígitos apresenta a correlação mais elevada com as de ortografia e fonologia simples. Por seu turno, a Nomeação de Formas/Cores apresenta uma maior correlação com a leitura de pseudopalavras de ortografia simples e fonologia complexa e com a escrita de pseudopalavras de ortografia complexa e fonologia simples.

Note-se que há uma superioridade dos valores respeitantes à Nomeação Rápida de Formas/Cores em relação à Nomeação Rápida de Dígitos no que toca às várias variáveis que correspondem à composição escrita, nomeadamente com os parâmetros relativos à linguagem contextual da história e construção da mesma (por ex., número de frases complexas, número de palavras correctamente escritas, com 3 ou mais sílabas, início da história). O mesmo se verificou com o número de palavras escritas aos 15 minutos e o número total de palavras.

No que se refere à leitura do texto, é possivel observar que as correlações mais elevadas dos testes de Nomeação Rápida de Dígitos e Formas/Cores se registam com o tempo de leitura e com o número total de palavras correctamente lidas, isto é, com medidas de velocidade e fluência da leitura.

Apesar das correlações serem mais elevadas nos testes de Consciência Fonológica, o teste de Compreensão de Instruções apresenta correlações significativas com a maior parte das medidas de leitura e de escrita. Observa-se, ainda, que apesar de se tratar de um teste que avalia a linguagem receptiva ao nível sintáctico, evidencia associações com medidas correspondentes ao nível da composição escrita (número total de frases complexas; utilização de conjunções coordenativas) similares às relativas a outras variáveis. 
Quadro 4. Correlações entre a linguagem oral, a escrita e a leitura para o $1 .^{\circ}$ ano

\begin{tabular}{|c|c|c|c|c|}
\hline & $\begin{array}{c}\mathrm{CFe}^{1} \\
(\mathrm{~N}=40)\end{array}$ & $\begin{array}{c}\mathrm{CFs}^{2} \\
(\mathrm{~N}=40)\end{array}$ & $\begin{array}{c}N_{R c^{3}} \\
(\mathrm{~N}=33)\end{array}$ & $\begin{array}{c}\mathrm{Cl}^{4} \\
(\mathrm{~N}=4 \mathrm{O})\end{array}$ \\
\hline Escrita Palavras Irregulares & $.49^{* *}$ & $.50^{* *}$ & -.15 & $.33^{*}$ \\
\hline Escrita Palavras Regulares & $.59^{* *}$ & $.58^{* *}$ & -.19 & $.37^{*}$ \\
\hline Escrita Palavras Total & $.57^{* *}$ & $.57^{* *}$ & -.18 & $.37^{*}$ \\
\hline Escrita Pseudopalavras O/F Simples 5 & $.52^{* *}$ & $.54^{* *}$ & -.33 & $.51^{*}$ \\
\hline Escrita Pseudopalavras OC/FS 6 & $.55^{* *}$ & $.56^{* *}$ & -.23 & .25 \\
\hline Escrita Pseudopalavras OS/FC7 & $.66^{* *}$ & $.58^{* *}$ & -.34 & $.38^{*}$ \\
\hline Escrita Pseudopalavras Total & $.66^{* *}$ & $.63^{* *}$ & -.33 & $.39^{*}$ \\
\hline Número Total Palavras N D Inc Esc. ${ }^{8}$ & -.10 & .11 & -.19 & -.02 \\
\hline Número Total Palavras Inc Esc. ${ }^{9}$ & -.09 & .03 & -.16 & .03 \\
\hline Número Total Frases Complexas & .18 & .23 & -.22 & .11 \\
\hline Conjunções Coordenativas & .26 & $.43^{* *}$ & -.07 & .20 \\
\hline Número Palavras Correct Esc. $3^{10}$ & $.56^{* *}$ & $.67^{* *}$ & -.18 & $.52^{* *}$ \\
\hline Início História & .27 & .30 & -.16 & $.27^{*}$ \\
\hline Sequência História & $.66^{* *}$ & $.62^{* *}$ & -.32 & $.38^{* *}$ \\
\hline Prosa Forma Escrever & $.54^{* *}$ & $.51^{* *}$ & -.26 & $.41^{* *}$ \\
\hline Número Total Palavras $15 \mathrm{~min}$ & .30 & $.52^{* *}$ & -.17 & $.41^{*}$ \\
\hline Número Total Palavras & .29 & $.36^{*}$ & -.24 & .26 \\
\hline Leitura Letras & $.31^{*}$ & $.36^{*}$ & -.11 & $.32^{*}$ \\
\hline Leitura Palavras Regulares & $.69^{* *}$ & $.63^{* *}$ & -.19 & $.39^{*}$ \\
\hline Leitura Palavras Irregulares & $.63^{* *}$ & $.55^{* *}$ & -.18 & $.37^{*}$ \\
\hline Leitura Palavras Total & $.69^{* *}$ & $.62^{* *}$ & -.19 & $.39^{*}$ \\
\hline Leitura Pseudopalavras O/F Simples" & .28 & $.44^{* *}$ & -.00 & .25 \\
\hline Leitura Pseudopalavras OC/FS'12 & $.53^{* *}$ & $.45^{* *}$ & -.13 & .15 \\
\hline Leitura Pseudopalavras OS/FC ${ }^{13}$ & $.49^{* *}$ & $.49^{* *}$ & -.15 & .31 \\
\hline Leitura Pseudopalavras Total & $.54^{* *}$ & $.53^{* *}$ & -.12 & .26 \\
\hline Leitura Texto Tempo Total & $-.46^{* *}$ & $-.45^{* *}$ & .20 & $-.31^{*}$ \\
\hline Leitura Texto Total Palavras & $.57^{* *}$ & $.56^{* *}$ & -.14 & $.34^{*}$ \\
\hline Leitura Texto Tempo/Palavras & $.47^{* *}$ & $.54^{* *}$ & -.25 & $.36^{*}$ \\
\hline
\end{tabular}

${ }^{*} \mathrm{p}<.05^{* *} \mathrm{p}<.01$

' CFe - Consciência Fonológica eliminação; ${ }^{2}$ CFs - Consciência Fonológica substituição; ${ }^{3}$ NRc - Nomeação Rápida de cores; ${ }^{4} \mathrm{Cl}$ - Compreensão de Instruções; ${ }^{5}$ Escrita Pseudopalavras O/F Simples - Escrita de Pseudopalavras de Ortografia e Fonologia Simples; ${ }^{6}$ Escrita Pseudopalavras OC/FS - Escrita de Pseudopalavras de Ortografia Complexa e Fonologia Simples; ${ }^{7}$ Escrita Pseudopalavras OS/FC - Escrita de Pseudopalavras de Ortografia Simples e Fonologia Complexa; ${ }^{8}$ Número Total Palavras N D Inc Esc. - Número Total de Palavras Não Duplicadas Incorrectamente Escritas; 9 Número Total Palavras Inc Esc. - Número Total de Palavras Incorrectamente Escritas; ${ }^{10}$ Número Palavras Correct Esc. 3 - Número de Palavras Correctamente Escritas com 3 ou mais Sílabas; "Leitura Pseudopalavras O/F simples - Leitura de Pseudopalavras de Ortografia Simples e Fonologia Simples; ${ }^{12}$ Leitura Pseudopalavras OC/FS - Leitura de Pseudopalavras de Ortografia Complexa e Fonologia Simples; ${ }^{13}$ Leitura Pseudopalavras OS/FC - Leitura de Pseudopalavras de Ortografia Simples e Fonologia Complexa.

No âmbito da análise dos dados por ano de escolaridade, começamos por chamar a atenção para o facto de, no $1 .^{\circ}$ ano, ser apenas contemplada a Nomeação de Cores (destinada, na BANC, a crianças com idades compreendidas entre os 5 e 6 
anos), uma vez que a Nomeação de Dígitos e de Formas/Cores são utilizadas com crianças entre os 7 e os 15 anos, sendo, por isso, maioritariamente aplicadas no $2 .^{\circ}$ ano de escolaridade (à excepção de 7 sujeitos do $1 .^{\circ}$ ano que já tinham idades requeridas para a aplicação dos testes).

No $1 .^{\circ}$ ano de escolaridade, é clara a primazia dos testes de Consciência Fonológica em relação às restantes medidas da linguagem oral, registando correlações significativas com a maior parte dos resultados das provas de escrita e de leitura (cf. Quadro 4). Note-se que os resultados vão no mesmo sentido dos assinalados na amostra total, designadamente, a maior associação da Consciência Fonológica com a escrita e leitura de palavras regulares, bem como com a escrita e leitura de pseudopalavras de ortografia simples e fonologia complexa. Neste último caso, constitui-se como excepção a relação do teste de Eliminação com a leitura de pseudopalavras, em que se verifica um valor mais elevado entre este teste e a leitura de pseudopalavras de ortografia complexa e fonologia simples.

Ao contrário do que seria de prever, e como é patente no Quadro 4, as medidas de fluência da escrita (por ex., número total de palavras aos 15 minutos, número total de palavras) obtiveram correlações moderadas e significativas com o teste de Substituição, mas não com o teste de Nomeação Rápida de Cores. Na leitura, as medidas de fluência (por ex: leitura do texto tempo total) também obtiveram correlações mais elevadas com os testes de Consciência Fonológica do que com o teste de Nomeação Rápida de Cores.

Por comparação com o que se verificou na amostra total, no $1 .^{\circ}$ ano, os valores respeitantes ao teste de Compreensão de Instruções foram mais modestos.

Deste modo, constatamos que a Consciência Fonológica mostrou, mais uma vez, ser a medida de linguagem oral com maior ligação com as provas de escrita e de leitura.

Quadro 5. Correlações entre a linguagem oral, a escrita e a leitura para o $2 .^{\circ}$ ano

\begin{tabular}{lccccc}
\hline & $\begin{array}{c}\mathrm{CFe}^{1} \\
(\mathrm{~N}=40)\end{array}$ & $\begin{array}{c}\mathrm{CFs}^{2} \\
(\mathrm{~N}=40)\end{array}$ & $\begin{array}{c}\mathrm{NRd}^{3} \\
(\mathrm{~N}=40)\end{array}$ & $\begin{array}{c}\mathrm{NRf}^{2} \mathrm{c}^{4} \\
(\mathrm{~N}=40)\end{array}$ & $\begin{array}{c}\mathrm{Cl}^{5} \\
(\mathrm{~N}=40)\end{array}$ \\
\hline Escrita Palavras Irregulares & $.61^{* *}$ & $.66^{* *}$ & $-.53^{* *}$ & $-.62^{* *}$ & .21 \\
Escrita Palavras Regulares & $.59^{* *}$ & $.68^{* *}$ & $-.55^{* *}$ & $-.54^{* *}$ & .09 \\
Escrita Palavras Total & $.67^{* *}$ & $.74^{* *}$ & $-.60^{* *}$ & $-.64^{* *}$ & .18 \\
Escrita Pseudopalavras O/F Simples & $.48^{* *}$ & $.54^{* *}$ & $-.56^{* *}$ & $-.51^{* *}$ & .12 \\
Escrita Pseudopalavras OC/FS7 & $.58^{* *}$ & $.62^{* *}$ & $-.54^{* *}$ & $-.59^{* *}$ & .09 \\
Escrita Pseudopalavras OS/FC & $.48^{* *}$ & $.56^{* *}$ & $-.48^{* *}$ & $-.51^{* *}$ & .14 \\
Escrita Pseudopalavras Total & $.55^{* *}$ & $.61^{* *}$ & $-.56^{* *}$ & $-.57^{* *}$ & .12 \\
Número Total Palavras N D Inc Esc. & $-.43^{* *}$ & $-.46^{* *}$ & $.60^{* *}$ & $.51^{* *}$ & -.05 \\
Número Total Palavras Inc Esc. ${ }^{10}$ & $-.54^{* *}$ & $-.57^{* *}$ & $.47^{* *}$ & $.45^{* *}$ & -.11
\end{tabular}


Quadro 5. (continuação)

\begin{tabular}{lccccc}
\hline & $\begin{array}{c}\mathrm{CFe}^{1} \\
(\mathrm{~N}=40)\end{array}$ & $\begin{array}{c}\mathrm{CFs}^{2} \\
(\mathrm{~N}=40)\end{array}$ & $\begin{array}{c}\mathrm{NRd}^{3} \\
(\mathrm{~N}=40)\end{array}$ & $\begin{array}{c}\mathrm{NRf}^{4} \mathrm{c}^{4} \\
(\mathrm{~N}=40)\end{array}$ & $\begin{array}{c}\mathrm{Cl}^{5} \\
(\mathrm{~N}=40)\end{array}$ \\
\hline Número Total Frases Complexas & .28 & $.44^{* *}$ & -.21 & $-.49^{* *}$ & .19 \\
Conjunções Coordenativas & $.36^{*}$ & .29 & -.26 & -.09 & .07 \\
Número Palavras Correct Esc. $3^{11}$ & $.29^{*}$ & $.45^{*}$ & -.22 & $-.46^{* *}$ & .22 \\
Início História & .28 & $.54^{* *}$ & -.20 & -.31 & .13 \\
Sequência História & $.36^{*}$ & $.53^{* *}$ & -.21 & $-.33^{*}$ & $.41^{* *}$ \\
Prosa Forma Escrever & .33 & $.44^{* *}$ & -.21 & $-.40^{*}$ & .10 \\
Número Total Palavras 15min & .16 & .15 & -.19 & $-.39^{*}$ & .06 \\
Número Total Palavras & .10 & .26 & -.14 & $-.30^{*}$ & .11 \\
\hline Leitura Letras & $.39^{* *}$ & $.46^{* *}$ & -.06 & -.16 & $.36^{*}$ \\
Leitura Palavras Regulares & $.51^{* *}$ & $.62^{* *}$ & $-.78^{* *}$ & $-.54^{* *}$ & .17 \\
Leitura Palavras Irregulares & $.63^{* *}$ & $.74^{* *}$ & $-.67^{* *}$ & $-.58^{* *}$ & .21 \\
Leitura Palavras Total & $.58^{* *}$ & $.69^{* *}$ & $-.76^{* *}$ & $-.58^{* *}$ & .20 \\
Leitura Pseudopalavras O/F Simples ${ }^{12}$ & $.40^{*}$ & $.46^{* *}$ & $-.81^{* *}$ & $-.54^{* *}$ & .08 \\
Leitura Pseudopalavras OC/FS'3 & $.54^{* *}$ & $.60^{* *}$ & $-.77^{* *}$ & $-.54^{* *}$ & .27 \\
Leitura Pseudopalavras OS/FC14 & $.59^{* *}$ & $.70^{* *}$ & $-.69^{* *}$ & $-.43^{* *}$ & .21 \\
Leitura Pseudopalavras Total & $.56^{* *}$ & $.64^{* *}$ & $-.83^{* *}$ & $-.57^{* *}$ & .16 \\
Leitura Texto Tempo Total & $-.46^{* *}$ & $-.55^{* *}$ & $.89^{* *}$ & $.56^{* *}$ & -13 \\
Leitura Texto Total Palavras & $.51^{* *}$ & $.60^{* *}$ & $-.85^{* *}$ & $-.50^{* *}$ & .19 \\
Leitura Texto Tempo/Palavras & $.43^{* *}$ & $.50^{* *}$ & $-.44^{* *}$ & $-.54^{* *}$ & .10 \\
Compreensão & .24 & $.37^{*}$ & $-.44^{* *}$ & -.26 & .05 \\
\hline
\end{tabular}

${ }^{*} p<.05{ }^{* *} p<.01$

${ }^{1}$ CFe - Consciência Fonológica eliminação; ${ }^{2} \mathrm{CFs}$ - Consciência Fonológica substituição; ${ }^{3} \mathrm{NRn}$ - Nomeação Rápida de dígitos; ${ }^{4} \mathrm{NRf} / \mathrm{C}$ - Nomeação Rápida de formas/cores; ${ }^{5} \mathrm{Cl}$ - Compreensão de Instruções; ${ }^{6}$ Escrita Pseudopalavras O/F Simples - Escrita de Pseudopalavras de Ortografia e Fonologia Simples; 7 Escrita Pseudopalavras OC/FS - Escrita de Pseudopalavras de Ortografia Complexa e Fonologia Simples; ${ }^{8}$ Escrita Pseudopalavras OS/FC - Escrita de Pseudopalavras de Ortografía Simples e Fonologia Complexa; ${ }^{9}$ Número Total Palavras N D Inc Esc. - Número Total de Palavras Não Duplicadas Incorrectamente Escritas; ${ }^{10}$ Número Total Palavras Inc Esc. - Número Total de Palavras Incorrectamente Escritas; "Número Palavras Correct Esc. 3 - Número de Palavras Correctamente Escritas com 3 ou mais Sillabas; 12 Leitura Pseudopalavras O/F simples - Leitura de Pseudopalavras de Ortografia Simples e Fonologia Simples; ${ }^{13}$ Leitura Pseudopalavras OC/FS - Leitura de Pseudopalavras de Ortografia Complexa e Fonologia Simples; ${ }^{14}$ Leitura Pseudopalavras OS/FC - Leitura de Pseudopalavras de Ortografia Simples e Fonologia Complexa.

Ao contrário dos resultados obtidos ao nível do $1 .{ }^{\circ}$ ano, no $2 . .^{\circ}$ ano (cf. Quadro 5), a superioridade da Consciência Fonológica relativamente às restantes medidas de linguagem oral já não é tão vincada, uma vez que as medidas de Nomeação Rápida (Dígitos e Formas/Cores) mostraram estar também muito relacionadas com a leitura e com a escrita.

No $2 .^{\circ}$ ano, os testes de Consciência Fonológica obtêm correlações mais elevadas com a escrita e leitura de palavras irregulares, à excepção do valor obtido no teste de Substituição e escrita de palavras irregulares, que é ligeiramente inferior ao registado entre este teste e a escrita de palavras regulares. Evidenciou-se também um padrão diferencial de associações entre os instrumentos de avaliação da Consciência 
Fonológica e as pseudopalavras, sendo que na escrita os valores mais elevados se registam com as de ortografia complexa e fonologia simples, enquanto que na leitura se mantém uma maior associação às de ortografia simples e fonologia complexa. Note-se que estes resultados vão contra o padrão de resultados obtidos ao nível da amostra total, bem como ao nível do $1 .^{\circ}$ ano, essencialmente no que diz respeito à relação com as palavras irregulares, sendo que até aqui, os testes de Consciência Fonológica obtiveram correlações mais elevadas com palavras regulares.

Tal como na amostra total, verificamos a elevada relação das medidas de Consciência Fonológica com a leitura do texto, essencialmente ao nível do teste de Substituição.

No que respeita à Nomeação de Dígitos, os resultados obtidos revelam uma associação muito próxima entre este instrumento e a escrita de palavras regulares e irregulares, enquanto que na leitura há uma ligação mais estreita com as palavras regulares. Este padrão de resultados é, apenas, parcialmente dissonante do constatado ao nivel da amostra total, já que nesta última a primazia é dada às palavras irregulares na escrita e às palavras regulares na leitura. Ao contrário do que aconteceu no $1 .{ }^{\circ}$ ano (superioridade da Consciência Fonológica inclusive em relação à fluência), é de salientar as elevadas correlações entre a Nomeação de Dígitos e as medidas de fluência da leitura, nomeadamente o tempo total de leitura do texto, bem como com o total de palavras lidas.

Por sua vez, a Nomeação de Formas/Cores apresentou um padrão de correlações muito semelhante ao já descrito para a amostra total: maior associação com a escrita e a leitura de palavras irregulares, com a escrita de pseudopalavras de ortografia complexa e fonologia simples, bem como com a leitura de pseudopalavras de ortografia e fonologia simples; elevada ligação às diferentes variáveis da composição escrita e a medidas de fluência da leitura.

É de salientar que o teste Compreensão de Instruções apresenta valores menos elevados, bem como menos significativos que no $1 .^{\circ}$ ano de escolaridade.

\section{Discussão}

Os resultados obtidos salientam a presença de uma forte relação entre a linguagem oral e a linguagem escrita e confirmam, de forma inequívoca, a hipótese 1. Estes resultados vão de encontro ao que já havia sido referenciado por autores como Montgomery e Leonard (1998), Snowling e Stackhouse (1996), Supple (1998) e Shanahan (2006). Note-se, no entanto, que se trata de um estudo correlacional que não permite estabelecer o sentido das relações entre as variáveis. 
Tendo em conta a amostra total, verificamos que a Consciência Fonológica está mais relacionada com as competências de leitura e de escrita do que os restantes testes. Estes resultados confirmam a hipótese 2 e são consonantes com o que autores como Savage et al. (2005), Wagner et al. (1994, 1997), entre outros, defendem. No entanto, verificamos que, de forma geral, o teste de Substituição regista correlações mais elevadas do que o de Eliminação. Este padrão de resultados não é surpreendente, uma vez que o teste de Eliminação exige apenas a elisão de um fonema, enquanto que o teste de Substituição exige quer esta operação, quer a adição de outro(s) fonema(s) na mesma posição fonotáctica. Neste sentido, o teste de Substituição é mais exigente em termos de manipulação fonética e de mobilização da memória fonológica.

Atendendo aos resultados por ano de escolaridade, no $1 .^{\circ}$ ano, assiste-se igualmente a uma superioridade dos testes de Consciência Fonológica relativamente aos restantes testes de avaliação da linguagem oral. No $2 .^{\circ}$ ano, a Consciência Fonológica também apresenta correlações moderadas e elevadas. Os dados atestam que, no 1. ${ }^{\circ}$ ano, a relação dos testes de Consciência Fonológica com o resultado total da leitura e escrita de palavras é de .57 (Eliminação e Substituição) na escrita e de .69 (Eliminação) e .62 (Substituição) na leitura. No $2 .^{\circ}$ ano, os resultados foram também elevados, tanto ao nível da escrita (Eliminação $r=.67$; Substituição $r=.74$ ) como ao nível da leitura (Eliminação $r=.58$; Substituição $r=.69$ ). Estes são, de facto, resultados que se enquadram nos obtidos por outros autores. Por exemplo, no estudo de Wagner e colaboradores (1994), a relação entre uma tarefa de Eliminação Fonémica e a leitura de palavras foi de .61 , no $1 .^{\circ}$ ano, e de .65 , no $2 .^{\circ}$ ano. Mais recentemente, Cardoso-Martins e Pennington (2004) obtiveram correlações entre a consciência fonémica e a leitura de palavras de 71 para o $1 .^{\circ}$ ano e de .70 para o $2 .^{\circ}$, em crianças sem história familiar de dificuldades na leitura. Apesar da idade não aparentar afectar a relação entre a Consciência Fonológica e as competências de leitura/escrita, convém ter presente que, à medida que se progride na escolaridade, elas se influenciam mutuamente, sendo a própria aprendizagem da leitura fundamental no desenvolvimento da consciência fonémica (Perfetti, 1985; Swanson, Trainin, Necoechea \& Hammill, 2003).

Note-se que, tal como proposto pelo modelo da dupla via (Coltheart, Curtis, Atkins \& Haller, 1993), a Consciência Fonológica apresenta, no $1 .^{\circ}$ ano, uma relação superior com a escrita e leitura de palavras regulares do que com a de palavras irregulares, corroborando, deste modo, e de forma parcial a hipótese anteriormente levantada $\left(\mathrm{H}_{4}\right)$. Os valores obtidos são consonantes com o estudo realizado por Nilsen e Bourassa (2008), uma vez que estes autores obtiveram correlações de .47 para palavras regulares e de .31 para palavras irregulares. No entanto, no $2 .^{\circ}$ ano, esta situação inverte-se, verificando-se, em termos gerais, uma maior associação entre estes testes e a escrita e leitura de palavras irregulares. Isto poderá prender-se com o facto da criança, inicialmente, reconhecer uma palavra através da via fono- 
lógica ou sublexical, mas, à medida que progride na escolaridade e adquire maior conhecimento sobre o vocabulário, poderá aceder e reconhecer as palavras através de um recurso simultâneo aos dois tipos de vias utilizadas na descodificação, não efectuando qualquer diferenciação entre elas. No mesmo sentido, palavras regulares, inicialmente acedidas pela via fonológica ou sublexical, podem, devido a uma frequência elevada, passar a ser conhecidas pela via ortográfica ou lexical. Quer isto dizer que, para além da regularidade ou irregularidade, existem outros parâmetros linguísticos passíveis de esbaterem a diferenciação entre as vias de leitura (por ex., a frequência, o grau de opacidade ou transparência da linguagem escrita).

Os resultados apontam ainda para a elevada relação da Consciência Fonológica com a escrita de pseudopalavras, comparativamente aos restantes testes de avaliação da linguagem oral, confirmando, em parte, a hipótese 5 . Idêntica tendência, mas consideravelmente mais atenuada, está também patente nas associações entre a Consciência Fonológica e a leitura de pseudopalavras. Resultados semelhantes foram verificados por, por exemplo, Strattman e Hodson (2005) em relação à leitura de pseudopalavras $(r=.79)$ e por Kim (2007) em relação à escrita de pseudopalavras $(r=.48)$. Este padrão de resultados é compreensivel, na medida em que estas são palavras desconhecidas para a criança, assim, a única forma de serem lidas e escritas é através da descodificação ou codificação fonológica, isto é, da correspondência das letras ou grupos de letras aos sons que estas representam nas palavras familiares ou vice-versa (Cardoso-Martins \& Pennington, 2004).

Constatamos ainda, ao nivel da amostra total, uma elevada relação da Consciência Fonológica com as diferentes variáveis da composição escrita, se bem que seja necessário ter presente, o carácter algo esquemático da avaliação de algumas delas. No que respeita a variáveis referentes à ortografia, tais como o número total de palavras incorrectamente escritas e o número total de palavras correctamente escritas com 3 ou mais sílabas, os dados são consonantes com os obtidos por Strattman e Hodson (2005), sendo que, no seu estudo, a correlação entre tarefas de Consciência Fonológica e a ortografia foi de .71. No mesmo sentido, se pronunciam vários autores e investigações (Berninger, 2000; Rebelo \& Fonseca, 2001), já que o desenvolvimento da ortografia está estreitamente relacionado com duas etapas que se relacionam mutuamente, a alfabética/fonológica e a do conhecimento visual da palavra. Na primeira, a consciência e percepção dos sons assumem um papel central, sendo, por isso, compreensivel que a Consciência Fonológica obtenha correlações moderadas com a ortografia.

No que se refere à relação entre a Consciência Fonológica e os parâmetros da composição escrita relativos à fluência e à construção da história, há que salientar que a referida relação raramente tem sido analisada. Tendo em conta os diferentes anos de escolaridade, observamos que no $1 .^{\circ}$ ano, a Consciência Fonológica apre- 
senta correlações significativas com várias variáveis da composição, essencialmente ao nivel do teste de Substituição. Em relação a variáveis respeitantes à fluência (número total de palavras aos 15 minutos; número total de palavras), Berninger (2000) e Abbott e Berninger (1993) mencionam que a relação entre várias medidas de linguagem oral (incluindo as de segmentação silábica e fonémica) e a fluência na composição escrita é apenas significativa no $2 .^{\circ}$ e no $3 .^{\circ}$ ano de escolaridade. Esta situação não se verifica no presente estudo, uma vez que a Consciência Fonológica obteve correlações moderadas e significativas com variáveis relativas à fluência da composição escrita apenas no $10^{\circ}$ ano.

É ainda de salientar a elevada relação das medidas de Consciência Fonológica com as referentes à fluência na leitura do texto ao nível quer da amostra total, quer do $1 .^{\circ}$ e $2 .^{\circ}$ anos de escolaridade. Idênticos dados já haviam sido referenciados, em 2004, por Cardoso-Martins e Pennington, sendo que no seu estudo, obtiveram correlações significativas ( $r=.66$ no $1 .^{\circ}$ ano e $r=.65$ no $2 .^{\circ}$ ano) entre tarefas de Consciência Fonológica e a fluência na leitura, em crianças sem história familiar de dificuldades na leitura. Por conseguinte, os dados sugerem que a Consciência Fonológica ao facilitar a descodificação, pode promover a rapidez da leitura.

Os resultados indicam que as medidas de Nomeação Rápida também apresentam uma forte ligação com a aprendizagem da leitura e da escrita. Este facto já havia sido constatado por outros autores, nomeadamente por Bowers e Wolf (1993), Manis et al. (2000) e Nähri et al. (2004). No entanto, tal como Manis et al. (2000) e Cardoso-Martins e Pennington (2004) referiram, esta relação varia consoante o tipo de estímulos utilizados. Por exemplo, no estudo de Cardoso-Martins e Pennington (2004), e adoptando novamente como referência as crianças sem história familiar de dificuldades na leitura, a relação entre a Nomeação Rápida e medidas de linguagem escrita (ex., leitura de palavras), foi mais elevada na nomeação de letras e de dígitos do que na nomeação de cores e de objectos (1..$^{\circ}$ ano, letras/dígitos $r=.44$, cores/objectos $r=.25 ; 2 .^{\circ}$ ano, letras/dígitos $r=.46$, cores/objectos $r=.38$ ). No presente estudo, também se verifica uma tendência similar no que respeita à Nomeação de Dígitos e à Nomeação de Cores, se bem que o facto destes testes terem sido aplicados a crianças de diferentes níveis de escolaridade impossibilite qualquer comparação rigorosa.

Outro facto a ter em linha de conta diz respeito ao tipo de tarefa empregue, isto é, ao facto de se tratar de tarefas RAS (Rapid Alternating Stimulus) ou RSN-AC (Rapid Serial Naming - Alternate Category), as quais dizem respeito à apresentação alternada de estímulos referentes a duas ou mais categorias semânticas, ou de tarefas RAN (Rapid Automatized Naming) ou RSN-SC (Rapid Serial Naming - Single Category) que estão relacionadas com a apresentação de estímulos pertencentes a uma única categoria semântica. Neste sentido, no presente estudo, observam-se correlações mais elevadas aquando da Nomeação de Formas/Cores do que na Nomeação de 
Dígitos ao nível da escrita e ao nível de algumas medidas de leitura. Em 1994, Wagner et al. verificaram este padrão de resultados, sendo que, no seu estudo e em relação à identificação de palavras escritas, obtiveram valores superiores para a nomeação contínua e alternada de dígitos e letras $(r=.66)$ do que para a nomeação de estímulos referentes a uma categoria semântica apresentados de forma isolada (dígitos $r=.42$, letras $r=.42$ ). Idênticos resultados foram, também, apontados por Wolf e Denckla (2005). Convém, contudo, notar que o estudo das relações entre a Nomeação Rápida e a linguagem escrita tem privilegiado o recurso a tarefas RSN-SC focando, quase exclusivamente, a leitura. Neste sentido, os dados do presente estudo ampliam os disponiveis em relação às tarefas RSN-AC e ao seu impacto quer ao nivel da leitura, quer ao nível da escrita. Em particular, e ao contrário do que é mencionado na hipótese 8 , verifica-se uma ligeira superioridade da Nomeação de Formas/Cores, comparativamente à Nomeação de Dígitos, no que diz respeito à escrita de palavras e aos vários parâmetros de avaliação da composição escrita. Isto poderá dever-se à maior exigência e complexidade deste teste que requer o uso integral e coordenado da atenção, bem como de subprocessos perceptivos, conceptuais, lexicais, motores e de memória (Närhi et al., 2004).

Importa salientar que os valores obtidos ao nível dos testes de Nomeação Rápida de Dígitos e Formas/Cores, salvo uma excepção (Nomeação Rápida de Dígitos e leitura de palavras irregulares), são ligeiramente mais elevados quando se tratam de palavras irregulares do que de palavras regulares. Esta relação corrobora a hipótese 6 e vem de encontro ao que Manis et al. (2000), bem como Cardoso-Martins e Pennington (2004) salientaram. Para estes autores a Nomeação Rápida está grandemente relacionada com o conhecimento ortográfico das palavras. Assim, tal como postula o modelo da dupla via, as particularidades apresentadas por algumas palavras são, essencialmente, reconhecidas através de uma análise visual, isto é, através de uma representação ortográfica da palavra (Castro \& Gomes, 2000). Deste modo, é compreensivel a elevada associação deste teste com palavras que manifestam um maior grau de complexidade em termos de correspondência fonema/grafema ou vice-versa.

No que se refere à escrita e leitura de pseudopalavras, embora, em termos gerais, se tenha observado uma superioridade ao nível da Consciência Fonológica, a Nomeação Rápida também obteve resultados elevados. Estes dados confluem com os apontados por outros autores, quer em relação à língua inglesa (Savage et al., 2005), quer em relação a línguas mais transparentes do que o Inglês, tais como o Espanhol (Escribano, 2007) e o Alemão (Landerl, 2001). Por exemplo, Savage et al. (2005) verificaram uma forte associação entre a Nomeação Rápida de Dígitos e a leitura de pseudopalavras $(r=.45)$. Estes resultados poderão estar relacionados com o que Felton e Brown (1990) referiram, uma vez que, segundo estes autores, a Nomeação Rápida é um bom preditor das posteriores competências de leitura, inclusive, no que diz respeito ao 
reconhecimento das pseudopalavras, particularmente em crianças que manifestam dificuldades ao nível da leitura. Esta associação também reenvia para o grau em que a Nomeação Rápida é ou não parcialmente fonológica. Neste sentido, Wagner e Torgesen (1987) referem que a Nomeação Rápida pode ser entendida como uma competência do processamento fonológico, nomeadamente, a capacidade para recuperar códigos fonológicos na memória a longo termo, enquanto que outros autores (Escribano 2007; Savage et al., 2005; Wolf et al., 2002) consideram que os processos subjacentes à Nomeação Rápida são distintos, ainda que relacionados com os de índole fonológica. A associação às pseudopalavras poderá ainda dever-se ao facto das tarefas de Nomeação Rápida se relacionarem, segundo Manis, Seidenberg e Doi (1999), com qualquer medida de leitura, uma vez que partilham com ela muitos componentes, nomeadamente a coordenação visuo-motora, o acesso rápido ao nome e significado das palavras através da memória e a articulação.

É ainda importante salientar a elevada correlação dos testes de Nomeação Rápida com as medidas de velocidade e de fluência da leitura $\left(\mathrm{H}_{7}\right)$, essencialmente no que diz respeito à Nomeação de Dígitos, uma vez que esta é uma tarefa mais automática. Estes resultados corroboram o que diversos autores constataram nos seus estudos (Cardoso-Martins \& Pennington, 2004; Escribano, 2007; Landerl, 2001). Tal como também foi postulado no levantamento da hipótese 7 , nota-se a associação deste instrumento com as medidas de fluência da escrita, particularmente no que concerne à Nomeação de Formas/Cores e ao $2 .^{\circ}$ ano de escolaridade. Dada a restrição dos estudos referentes às conexões entre a Nomeação Rápida e a escrita, o presente estudo amplia para este domínio, o que já havia sido verificado em relação à leitura.

Tendo em conta a amostra total, o teste de Compreensão de Instruções aparenta também estar intimamente relacionado com as competências de literacia, corroborando a hipótese 3 no que a ele diz respeito. Assim, tal como é referido pelo Rand Reading Study Group Report (2000, cit. in Mokhari \& Thompson, 2006) e por Tunmer (1994), os aspectos sintácticos, entre outros, constituem pré-requisitos para um bom desempenho ao nível da leitura.

No $1 .^{\circ}$ ano, verificou-se uma relação mais importante entre o teste de Compreensão de Instruções e a escrita e leitura do que no $2 .^{\circ}$ ano de escolaridade. No entanto, os resultados são consonantes com o que Whitehurst (2001, cit. in Strattman \& Hodson, 2005) mencionou. De acordo com este autor, no $1 .^{\circ}$ e no $2 .^{\circ}$ ano de escolaridade, o conhecimento do alfabeto e a sensibilidade fonológica estão grandemente associados com o desempenho na leitura. Nos anos posteriores e, depois de conhecerem o código alfabético, as competências sintácticas e semânticas tornam-se mais importantes. Deste modo, o facto da Compreensão de Instruções obter correlações mais baixas do que a Consciência Fonológica ou a Nomeação Rápida, no $1 .^{\circ}$ e no $2 .^{\circ}$ ano de escolaridade, corrobora esta afirmação. 
Apesar de este ser um teste que avalia, essencialmente, a linguagem receptiva ao nível sintáctico, na composição escrita e ao nível da amostra total, particularmente em variáveis como o número total de frases complexas e a utilização de conjunções coordenativas para além do "e", este instrumento apresenta resultados semelhantes aos dos outros instrumentos de avaliação da linguagem oral, nomeadamente aos da Consciência Fonológica. Ainda assim, pode afirmar-se que a hipótese 9 é corroborada.

Em suma, confirmam-se as hipóteses 1 e 3 relativas a todas as dimensões da linguagem oral contempladas e às suas relações com a linguagem escrita. Num plano mais específico, e no que concerne à Consciência Fonológica, corrobora-se integralmente a hipótese 2 , relativamente à sua superioridade comparativa, e corroboram-se parcialmente as hipóteses 4 e 5 referentes às palavras regulares e às pseudopalavras. Já no que concerne à Nomeação Rápida, confirmam-se integralmente as respectivas ligações à leitura e escrita de palavras irregulares e à fluência, isto é, as hipóteses 6 e 7, enquanto que a hipótese 8 , que aponta para conexões mais importantes da Nomeação de Dígitos do que da Nomeação de Formas/Cores com a leitura e a escrita é refutada. Por último, a hipótese 9 , relativa à confluência da Compreensão de Instruções com medidas sintácticas na composição escrita é confirmada quando se atende à amostra na sua globalidade.

\section{Conclusão}

Os resultados obtidos ao nível das diferentes medidas de avaliação de competências linguísticas e metalinguísticas empregues neste estudo, atestam a validade concorrente das mesmas em relação a um domínio em que a sua utilização se afigura, particularmente, pertinente, isto é, a linguagem escrita. Constatámos também a estreita relação da linguagem oral com a escrita e a leitura, essencialmente ao nível dos testes de Consciência Fonológica e de Nomeação Rápida. Já a Compreensão de Instruções mostrou ser menos relevante.

O presente trabalho corroborou o facto da Consciência Fonológica estabelecer uma maior associação com a escrita de palavras regulares e com pseudopalavras, bem como o facto da Nomeação Rápida apresentar uma relação mais estreita com a leitura e escrita de palavras irregulares. Além disso, a Nomeação Rápida revelou estar associada à fluência na leitura e na escrita, se bem que de forma não predominante, já que, neste aspecto, a Consciência Fonológica também apresentou resultados elevados. Por seu turno, a Compreensão de Instruções demonstrou estar associada a variáveis relativas à sintaxe na composição escrita, quando se considera a amostra na sua globalidade, ainda que tais associações sejam semeIhantes às de outros instrumentos de avaliação da linguagem oral. 
Não obstante, persistem, ainda, questões em aberto, entre as quais se salientam as relativas à influência comparativa que a Consciência Fonológica e a Nomeação Rápida exercem ao nível da aprendizagem da leitura e da escrita da língua portuguesa. Se bem que reconhecendo-se que a análise destas questões requeria uma abordagem longitudinal, apontam-se, de seguida, outras vias de aprofundamento dos dados obtidos.

Assim, consideramos que seria útil utilizar uma amostra mais ampla, controlar a influência de variáveis potencialmente relevantes (por ex., nível intelectual, nível socioeconómico) e recorrer a técnicas multivariadas, tais como a regressão múltipla, com o objectivo de conhecer a variância explicada por cada instrumento e qual se afigura mais importante ao nivel da predição do desempenho em leitura e escrita. Note-se que esta técnica estatística não foi utilizada, devido ao facto do número da amostra ser inferior ao necessário, da distribuição das variáveis nem sempre ser normal e da presença de outliers.

Além disso, os testes de Nomeação de Dígitos e de Formas/Cores foram, apenas, contemplados no $2 .^{\circ}$ ano de escolaridade. No entanto, seria útil aplicá-los desde o $1^{\circ}$ ano, a fim de circunscrever, de forma completa, as conexões da Nomeação Rápida com a leitura e a escrita, bem como para estabelecer, com maior clareza, se os resultados variam consoante os anos de escolaridade.

Chamamos também, e uma vez mais, a atenção para o facto de, no presente estudo, as variáveis relativas à construção da história na composição serem avaliadas de forma esquemática. Neste sentido, seria profícuo proceder a uma avaliação consideravelmente mais aprofundada destas variáveis.

Por último, ressaltamos o facto do número de investigações sobre a escrita ser relativamente pobre em detrimento do relativo à leitura, pelo que, seria uma mais-valia aprofundar conhecimentos nesta área.

\section{Referências Bibliográficas}

Abbott, R., \& Berninger, V. W. (1993). Structural equation modeling of relationships among developmental skills and writing skills in primary- and intermediate- grade writers. Journal of Educational Psychology, 85, 475-805.

Albuquerque, C. P., Martins, C. R., \& Simões, M. R. (2007). Testes de Consciência Fonológica da Bateria de Avaliação Neuropsicológica de Coimbra. Educação, Temas e Problemas, 4, 101-118.

Berninger, V.W. (2000). Development of language by hand and its connections with language by ear, mouth, and eye. Topics in Language Disorders, 20(4), 65-84. 
Bowers, P. G., \& Wolf, M. (1993). Theoretical links among naming speed, precise timing mechanisms and orthographic skills in dyslexia. Reading and Writing: An Interdisciplinary Journal, 5, 64-85.

Cardoso-Martins, C., \& Pennington, F. B. (2004). The relationship between phoneme awareness and rapid serial naming skills and literacy acquisition: The role of developmental period and reading ability. Scientific Studies of Reading, 8, 27-52.

Felton, R., \& Brown, L. S. (1990). Phonological processes as predictors of specific reading skills in children at risk for reading failure. Reading and Writing, 2, 39-59.

Festas, I., Leitão, J. A., Formosinho, M. D., Albuquerque, C., Vilar, M., Martins, C., et al. (2006). PAL-PORT - Uma bateria de avaliação psicolinguística das afasias e de outras perturbações da linguagem para a população portuguesa. In C. Machado, L. Almeida, A. Guisande, M. Gonçalves., \& V. Ramalho (Eds.), XI Conferência Internacional Avaliação Psicológica: Formas e Contextos (pp. 719-729). Braga: Ed. Psiquilibrios.

Gaux, C., \& Gombert, I. E. (1999). Implicit and explicit syntactic knowledge and reading in pre-adolescents. British Journal of Educational Psychology, 17, 169-188.

Griffiths, Y. M., \& Snowling, M. J. (2001). Predictors of exception word and nonword reading in dyslexic children: The severity hypothesis. Journal of Educational Psychology, 94, 34-43.

Hammill, D. D., \& Larsen, S. C. (1996). Test of Written Language-Third Edition. Examiner's Manual. Austin: Pro-Ed.

Juel, C. (1998). Learning to read and write: A longitudinal study of 54 children from first through fourth grades. Journal of Educational Psychology, 80, 437-447.

Kim, Y. S. (2007). Phonological awareness and literacy skills in Korean: An examination of the unique role of body-coda units. Applied Psycholinguistics, 28, 69-94.

Landerl, K. (2001). Word recognition deficits in German: More evidence from a representative sample. Dyslexia, 7, 183-196.

Leikin, M., \& Breznit, Z. (2001). Effects of accelerated reading rate on processing words' syntactic functions by normal and dyslexic readers: Event related potentials evidence. The Journal of Genetic Psychology, 163, 276-279.

Lopes, A. F. (2007). Crianças e adolescentes com epilepsia: Estudos com a Bateria de Avaliação Neuropsicológica de Coimbra. Tese de Mestrado não publicada. Faculdade de Psicologia e de Ciências da Educação, Universidade de Coimbra.

Loureiro, C., Silva, L. R., \& Fernandes, T. (2002). Bateria de Avaliação da Leitura e Escrita. Lisboa: Laboratório de Estudos da Linguagem, Centro de Estudos Egas Moniz.

Manis, F. R., Bhadha, B., \& Doi, M. L. (2000). Naming speed, phonological awareness and orthographic knowledge in second graders. Journal of Learning Disabilities, 4, 325-334.

Manis, F. R., Seidenberg, M. S., \& Doi, L. M. (1999). See Dick RAN: Rapid naming and the longitudinal prediction of reading subskills in first and second graders. Scientific Studies of Reading, 3, 129-157. 
Martins, C. M.Z. (2005). Estudos de adaptação de um teste de escrita. Dissertação de Mestrado não publicada. Faculdade de Psicologia e de Ciências da Educação, Universidade de Coimbra.

Mokhari, K., \& Thompson, H. B. (2006). How problems of reading and comprehension are related to difficulties in syntactic awareness skills among fifth graders. The British Journal of Development, 46, 73-94.

Montgomery, W. J., \& Leonard, B. L. (1998). Real-time inflectional processing by children with specific language impairment: Effects of phonetics substance. Journal of Speech, Language and Hearing Research, 41, 1432-1443.

Närhi, V., Ahonen, T., Aro, M., Leppäsaari, T., Korhonen, T., Tolvanen, A., \& Lyytinen, H. (2004). Rapid serial naming: Relations between different stimuli and neuropsychological factors. Brain and Language, 92, 45-57.

Nilsen, E., \& Bourassa, D. (2008). Word-learning performance in beginning readers. Canadian Journal of Experimental Psychology, 62(2), 110-116.

Perfetti, C. A. (1985). Reading ability. New York: Oxford University Press.

Rebelo, J. A., \& Fonseca, A. C. (2001). Aprendizagem da escrita elementar em Português e suas dificuldades: Um estudo longitudinal. Revista Portuguesa de Pedagogia, 35(2), 31-63.

Sá, D. S. F. (2007). Avaliação neuropsicológica da Perturbação de Oposição e Desafio. Tese de Mestrado não publicada. Faculdade de Psicologia e de Ciências da Educação, Universidade de Coimbra.

Santos, L. M. G. (2006). Consequências neuropsicológicas, comportamentais e sócio-emocionais dos traumatismos crânio-encefálicos na infância e adolescência: Um estudo exploratório. Tese de Mestrado não publicada. Faculdade de Psicologia e de Ciências da Educação, Universidade de Coimbra.

Savage, S. R., Frederickson, N., Goodwin, R., Patnin, U., Smith, N., \& Tuersley, L. (2005) Relationships among rapid digit naming, phonological processing, motor automaticity, and speech perception in poor, average, and good readers and spellers. Journal of Learning Disabilities, 38, 12-28.

Shanahan, T. (2006). Relations among oral language, reading, and writing development. In C. McArthur, S. Graham, \& J. Fitzgerald (Eds.), Handbook of writing research (pp. 171-183). New York: Guilford Press.

Shiotsu, T., \& Weir, C. J. (2007). The relative significance of syntactic knowledge and vocabulary breadth in the prediction of reading comprehension test performance. Language Testing, 24, 99-128.

Simões, M. R., Albuquerque, C. P., Pinho, S., Pereira, M., Seabra Santos, M. J., Alberto, I., et al. (2000). Bateria de Avaliação Neuropsicológica de Coimbra (BANC): Manual. Coimbra: Serviço de Avaliação Psicológica, FPCE-UC.

Simões, M. R., Fernandes, E., Alfaiate, C., Vaz, C., Pereira, M. A., Albuquerque, C. P., et al. (2007). A Bateria de Avaliação Neuropsicológica de Coimbra (BANC): Estudo de validação num grupo de crianças com problemas de aprendizagem escolar. Comunicação apresentada no "XIII Seminário de Desenvolvimento", Coimbra, Portugal.

Snowling, M., \& Stackhouse, J. (1996). Dyslexia, speech and language. A practioners handbook. London: Whurr.

Strattman, K., \& Hodson, B. W. (2005) Variables that influence decoding and spelling in beginning readers. Child Language Teaching and Therapy, 21, 165-190. 
Supple, M. M. (1998). The relationship between oral and written language. Folia Phoniatrica et Logopaedica, 50, 243-255.

Swanson, L. H., Trainin, G., Necoechea, D., \& Hammill, D. (2003). Rapid naming, phonological awareness and reading: A meta-analysis of the correlation evidence. Review of Educational Research, 4, 407-440.

Tunmer, W. E. (1994). Phonological processing skills and reading remediation. In C. Hulme, \& M. J. Snowling (Eds.), Reading development and dyslexia (pp. 147-162). London: Whurr.

Tunmer, W. E., Herriman, M. L., \& Nesdale, A. R. (1988). Metalinguistic abilities and reading acquisition. British Journal of Developmental Psychology, 5, 25-34.

Tunmer, W. E., \& Hoover, W. (1992). Cognitive linguistic factors in learning to read. In P. B. Gough, L. C. Ehri, \& R. Treiman (Eds.), Reading acquisition (pp. 175-214). Hillsdale: Erlbaum.

Wagner, R. K., \& Torgesen, J. K. (1987). The nature of phonological processing and its causal role in the acquisition of reading skills. Psychological Bulletin, 101, 192-212.

Wagner, R. K., Torgesen, J. K., Rashotte, C. A. (1994). Development of reading-related phonological processing abilities: Evidence of bi-directional causality from a latent variable longitudinal study. Developmental Psychology, 30, 73-87.

Wagner, R. K., Torgesen, J. K., Rashotte, C. A., Hecht, S. A., Barker, T. A., \& Burgess, S. R. (1997). Changing relations between phonological processing abilities and word-level reading as children develop form beginning to skilled readers: A 5-year longitudinal study. Developmental Psychology, 33, 468-479.

Wolf, M., \& Denckla, M. B. (2005). Rapid Automatized Naming and Rapid Alternating Stimulus Tests. Examiner's Manual. Austin: Pro-Ed.

Wolf, M., Goldberg O'Rourke, A., Gidney, C., Lovett, M., Cirino, P., \& Morris, R. (2002). The second deficit: An investigation of the independence of phonological and naming speed deficits in developmental dyslexia. Reading and Writing: An Interdisciplinary Journal, 15, 43-72.

Young, A., \& Bowers, P. G. (1995). Individual differences and text difficulty determinants of reading fluency and expressiveness. Journal of Experimental Child Psychology, 60, 428-454.

\section{Relationships between Oral Language and Written Language}

This research intends to analyse relationships between oral language and written language in 80 children of the first and second grades. To do so, instruments of oral language assessment, that incorporate the Battery of Neuropsychology Assessment of Coimbra (Phonological Awareness, Rapid Naming and Instructions' Comprehension), and writing and reading tasks of the Labling and PAL-Port have been used. Phonological Awareness revealed a strong association with several measures of reading and writing performance, with particular emphasis on the first grade of school. On the other hand, Rapid Naming showed more relevance on the second grade. Comparatively to the previous measures, Instructions' Comprehension revealed to be less associated with writing and reading.

KEYWORDS: Oral Language; Writing; Reading. 